\title{
Genetic forms of severe insulin resistance: what endocrinologists should know
}

\author{
Victoria E R Parker and Robert K Semple \\ The University of Cambridge Metabolic Research Laboratories, Institute of Metabolic Science, Cambridge CB2 OQQ, UK \\ (Correspondence should be addressed to R K Semple; Email: rks16@cam.ac.uk)
}

\begin{abstract}
'Insulin resistance' (IR) is a widely used clinical term. It is usually defined as a state characterised by reduced glucose-lowering activity of insulin, but it is also sometimes used as a shorthand label for a clinical syndrome encompassing major pathologies such as type 2 diabetes, polycystic ovary syndrome, fatty liver disease and atherosclerosis. Nevertheless, the precise cellular origins of IR, the causal links among these phenomena and the mechanisms underlying them remain poorly understood or contentious. Prevalent IR usually results from a genetic predisposition interacting with acquired obesity; however, even in some lean individuals, very severe degrees of IR can be observed. It is important to identify these people as they often harbour identifiable single-gene defects and they may benefit from molecular diagnosis, genetic counselling and sometimes tailored therapies. Observation of people with known single-gene defects also offers the opportunity to make inferences about the mechanistic links between IR and common pathologies. Herein, we summarise the currently known monogenic forms of severe IR, with an emphasis on the practical aspects of their recognition, diagnosis and management. In particular, we draw distinctions among the biochemical subphenotypes of IR that arise from primary adipose tissue dysfunction or from primary insulin signalling defects and discuss the implications of this dichotomy for management.
\end{abstract}

European Journal of Endocrinology 169 R71-R80

\section{Introduction}

Obesity and the metabolic syndrome pose a substantial threat to health and longevity in contemporary society. Integral to this is the propensity of obesity to induce a state of insulin resistance (IR), or reduced responsiveness to the glucose-lowering action of insulin in some, but not all, people. Evidence from twin studies suggests that a significant part of this individual susceptibility is genetically determined $(1,2,3,4)$; however, populationbased, genome-wide association studies have been largely ineffective to date in uncovering the precise genetic variants accounting for this. Improving our understanding of both the mechanisms leading to IR susceptibility and the mechanisms linking it to disease is imperative, as IR is strongly associated with, and in some cases the driver of, major morbidity and mortality in the form of diabetes mellitus (5), the spectrum of fatty liver disease $(6,7)$, atherosclerosis $(8)$, ovulatory dysfunction (9) and malignancy (10).

Syndromes of severe IR (SSIRs) will be used in this article to denote a group of rare disorders that feature severe IR (SIR) that is not accounted for by commensurately severe obesity. In fact, in the majority of conditions to be described, the affected individuals are usually lean. No formal criteria for diagnosing SIR biochemically exist. In our own practice, we use a fasting insulin value $>150 \mathrm{pmol} / \mathrm{l}$ and/or a peak insulin value on glucose tolerance testing $>1500 \mathrm{pmol} / \mathrm{l}$ in individuals with a BMI $<30 \mathrm{~kg} / \mathrm{m}^{2}$ and with normal glucose tolerance as a useful indicator, while in those with absolute insulin deficiency and a BMI $<30 \mathrm{~kg} / \mathrm{m}^{2}$, exogenous insulin requirement of $>3$ units $/ \mathrm{kg}$ per day is suggestive. However, it is important to emphasise that such biochemical criteria should not be applied rigidly. This is partly because of the difficulty in interpreting insulin levels once partial $\beta$-cell decompensation has occurred, as in many patients at first evaluation, and partly because of the influence of age, pubertal status and adiposity on insulin levels in the general population. Thus, while some biochemical testing is of great value, it should be interpreted in the light of clinical features including acanthosis nigricans, oligomenorrhoea and hyperandrogenism, or features specific to individual syndromes such as abnormal adipose distribution. The prevalence of SSIRs has not been formally assessed, though quaternary referral practice in our centre suggests a prevalence of the order of $0.1-0.5 \%$ among patients visiting hospital diabetes clinics (11). 
It is important to understand that while biochemically confirmed SIR is a convenient defining feature of SSIRs, SIR per se is a biochemical state shared by many heterogeneous disorders. These may be acquired, with SIR being attributable to critical illness or pharmacotherapy or, in rare cases, to anti-insulin receptor antibodies $(12,13)$ or to the destruction of some or all adipose tissue $(14,15)$. As these disorders have been thoroughly reviewed $(13,16,17,18,19)$, the focus of this article will be on genetic SSIRs.

Over the past 25 years, the pace of genetic discovery in the field of SSIRs has been intensifying as the power and reach of genetic technologies have advanced (20, 21). However, the genetic landscape of SSIRs has not evolved as initially anticipated, for although pathogenic mutations have been identified in several critical molecules directly involved in insulin signalling, the majority of patients have proved to have primary genetic defects affecting adipose tissue development or function or indeed affecting other cellular processes such as DNA repair, whose link to SIR is yet to be fully elucidated. We have incorporated these discoveries into a classification scheme for SSIRs that distinguishes primary insulin signalling disorders, primary lipodystrophies and complex, more pleiotropic disorders (11) (Table 1). This has been facilitated by a growing ability to subphenotype SSIRs clinically and biochemically prior to genetic testing $(22,23,24)$, and this approach holds further promise for the future in permitting customised therapeutic approaches to each condition.

In many SSIRs, abnormal glucose homeostasis is not the presenting problem, with the first clinical contact often being with paediatricians, endocrinologists, dermatologists, lipidologists or gynaecologists, among others. This review aims, first, to highlight the classical presentations of genetic SSIRs and, second, to outline the principles of investigation and management that have emerged from specialised clinical practice.

Table 1 Classification of the syndromes of severe insulin resistance.

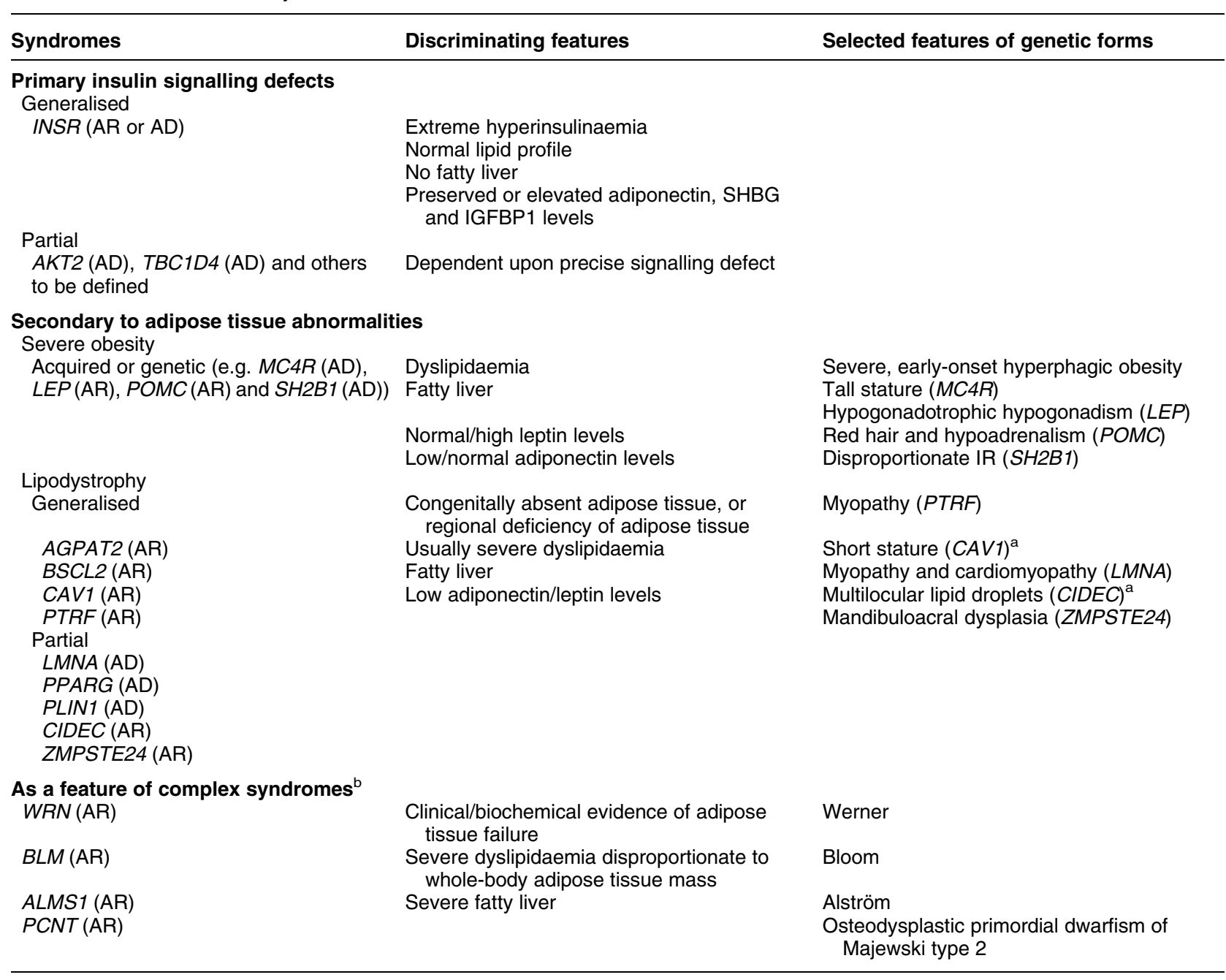

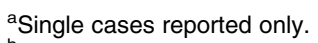

bummary of clinical features in Table 2. 
SSIRs presenting peri- or postpubertally will be considered first, followed by the much rarer, predominantly autosomal recessive SSIRs that usually present in infancy or in prepubertal children.

\section{SSIRs presenting peri- or postpubertally}

SSIRs most commonly present to clinical attention in the peripubertal period, although in many cases severe hyperinsulinaemia is congenital. Usually, it is the symptoms arising from ovarian dysfunction that trigger medical consultation. Puberty is often accelerated in those with SSIRs, most probably due to the action of hyperinsulinaemia, which exerts synergistic effects with gonadotrophins on the ovary $(25,26)$. Many SSIRs are biochemically and clinically more severe in females, so that index cases in the large majority of affected families are female. To illustrate some of the diagnostic and therapeutic issues that arise in SSIRs, several representative case vignettes are described below.

\section{Case 1: a lean adolescent with hirsutism, polycystic ovaries and acanthosis nigricans}

A 15-year-old girl was referred to a specialist SIR clinic with hirsutism and primary amenorrhoea. Coarse facial hair had first been noticed at 12 years of age and had subsequently become progressively more severe and cosmetically distressing. There was a history of diabetes in a paternal grandmother.

Investigation at initial presentation revealed enlarged ovaries with multiple peripheral cysts (Fig. 1A), an elevated LH:FSH ratio and a strikingly high testosterone level of $8.2 \mathrm{nmol} / \mathrm{l}$. DHEAS levels were normal, and
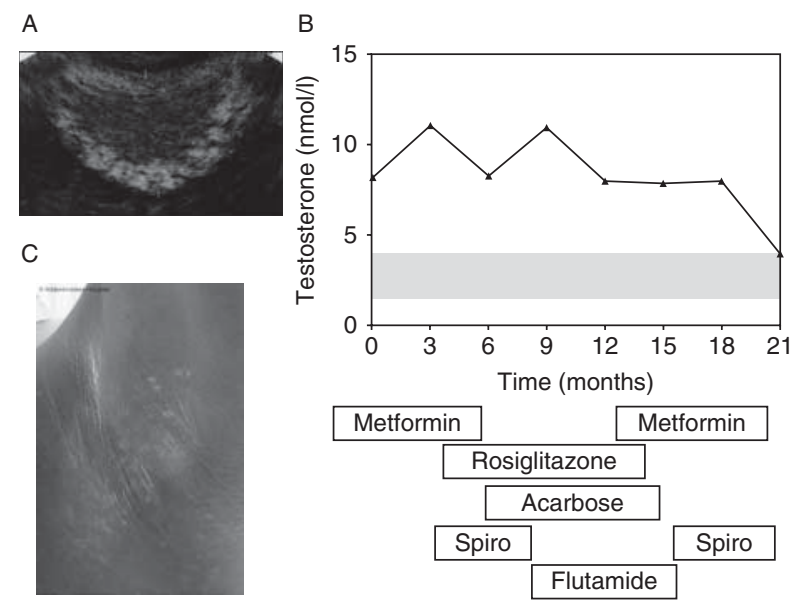

Figure 1 Case 1. (A) Ultrasound appearance of the ovary at 12 years of age showing multiple circumferential cysts. (B) Serial testosterone measurements and concurrent therapeutic regimen. Spiro, spironolactone; grey-shaded area represents normal female range. (C) Axillary acanthosis nigricans and acrochordons. subsequent ovarian vein sampling confirmed the serum testosterone to be of ovarian origin. Fasting insulin levels were extremely elevated at $1088 \mathrm{pmol} / \mathrm{l}$ (reference $<60 \mathrm{pmol} / \mathrm{l}$ ) with a concomitant glucose level of $3.4 \mathrm{mmol} / \mathrm{l}$. Pharmacological therapy including metformin, rosiglitazone, acarbose and antiandrogenic therapy was used over the next 2 years, with gradual improvement of hyperandrogenaemia and hirsutism (Fig. 1B).

On re-evaluation at 16 years of age, her BMI was $21 \mathrm{~kg} / \mathrm{m}^{2}$ and height $1.52 \mathrm{~m}$. She had moderately severe acne and severe hirsutism affecting her face, chest and lower abdomen. Puberty was well advanced (Tanner stage 4). Acanthosis nigricans was prominent in both axillae (Fig. 1C), with numerous skin tags, and the patient volunteered that her mother had always scrubbed her neck when she was a child because it was 'dirty'. General examination was otherwise normal.

Severe hyperinsulinaemia persisted (fasting plasma insulin level $745 \mathrm{pmol} / \mathrm{l}$ ); however, the lipid profile was normal, and there was neither biochemical nor radiological evidence of fatty liver. Adiponectin levels were elevated at $17.7 \mu \mathrm{g} / \mathrm{l}(2.4-14.9)$. A genetic defect in the INSR gene, encoding the insulin receptor, was diagnosed, and sequencing identified a well-known dominant negative heterozygous missense mutation, Pro1178Leu.

Comment Hyperandrogenism with primary amenorrhoea or oligomenorrhoea is the commonest presentation of SIR, with acanthosis nigricans and hyperglycaemia often only being noticed on subsequent evaluation. Hyperandrogenism is usually particularly severe in the second decade, when pubertal IR interacts with the underlying genetic defect. Testosterone levels may be extremely high (up to $15 \mathrm{nmol} / \mathrm{l}$ ) and may induce some virilisation. Such hyperandrogenaemia commonly triggers a search for a virilising tumour; however, clinical experience suggests that testosterone levels may usually be lowered to the normal female range by the use of GNRH analogues to suppress gonadotrophin levels, as has been reported in postmenopausal hyperthecosis with severe hyperandrogenism and IR $(27,28,29)$. Nevertheless, bona fide virilising tumours have been described in the context of congenital SIR (30) (RK Semple, unpublished data), raising the possibility that sustained hyperinsulinaemia is a risk factor for the development of autonomous androgen-secreting tumours. More formal evaluation of the relative risks and benefits of a 'block-and-replace' strategy in young women with SIR-related hyperandrogenism, using GNRH agonists in conjunction with hormone replacement, is yet to be reported. Nevertheless, in our own practice, several examples of autonomous virilising tumours arising in the context of many years of SIR suggest that IR-related hyperandrogenaemia may not be an entirely benign entity, at least in the long term.

Although these ovarian features of IR are generic to nearly all forms of SSIRs, other aspects of insulin receptoropathy are distinct: dyslipidaemia and fatty liver are almost never a feature of proximal insulin 
signalling disorders (24), while inappropriately normal or high plasma adiponectin levels are characteristic $(23,31,32)$ and can be used to triage patents with SSIRs for INSR gene screening (33). Whether the apparently benign lipid profile and lack of fatty liver translate into long-term protection of patients with INSR mutations from atherosclerosis and fibrotic liver disease despite their SIR is yet to be determined.

\section{Case 2: the 'asymptomatic' male relative}

The 46-year-old father of a 15-year-old girl recently diagnosed with an INSR mutation was referred for genetic counselling. He insisted that he was in excellent health, but on detailed enquiry, a long-standing history of postprandial lightheadedness and sweating was established. On examination, he was lean, with marked acanthosis nigricans in the axillae and nuchal region. Fasting glucose levels were $7.8 \mathrm{mmol} / \mathrm{l}$, and HbA1c levels were suggestive of occult diabetes at $52 \mathrm{mmol} / \mathrm{mol}$. On prolonged glucose tolerance testing,
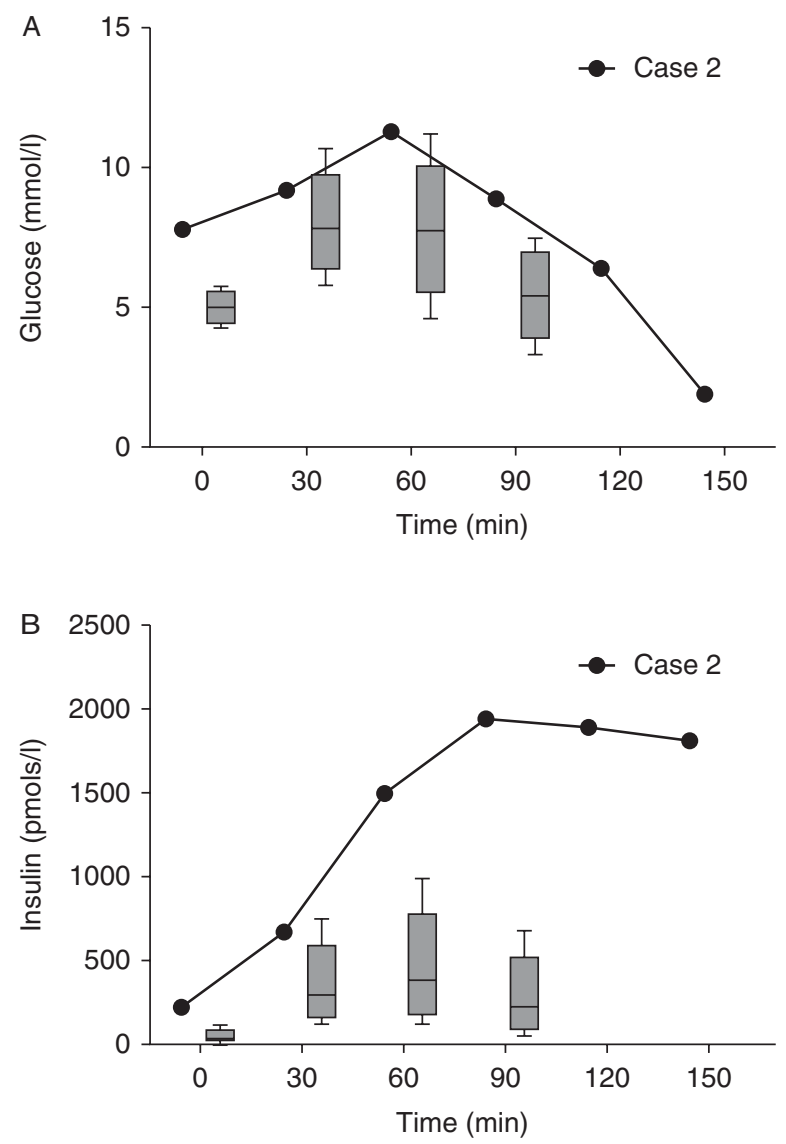

Figure 2 Results of $75 \mathrm{~g}$ oral glucose tolerance test in Case 2. (A) Glucose and (B) insulin levels in comparison with those of age- and sex-matched non-diabetic controls. Box and whiskers represent 5th and 95th centiles respectively (control data obtained from Prof. Nicholas J Wareham, MRC Epidemiology Unit, Cambridge (67)). his blood glucose levels fell to $1.9 \mathrm{mmol} / \mathrm{l}$ at $150 \mathrm{~min}$, with concomitant sweating and confusion, and plasma insulin levels were subsequently found to be severely elevated at $1872 \mathrm{pmol} / \mathrm{l}$ (Fig. 2). The lipid profile and indices of liver function were normal, and the presence of the INSR mutation was confirmed. A low-glycaemic index diet, acarbose and advice on snacking between meals helped to alleviate postprandial hypoglycaemia.

Comment IR is commonly less severe in men than in women, even in the face of the same underlying genetic defect. Compounding this, the lack of the 'early warning' signs of oligomenorrhoea and clinical hyperandrogenism means that men are commonly either undiagnosed or simply diagnosed with 'type 2 diabetes' in mid-life. SSIRs are thus identified far more frequently in females than in males, and after diagnosis of a girl with SIR, it is very common in autosomal dominant cases later to diagnose occult SIR and diabetes in her father. As in this case, hypoglycaemia may be a major feature of SIR due to either insulin receptor dysfunction or lipodystrophy and may be sufficiently severe to cause neuroglycopaenia and loss of consciousness. This may be the presenting feature of a SSIR, although as $\beta$-cells decompensate hypoglycaemia lessens and hyperglycaemia comes to dominate. It is not uncommon for detailed work-ups for primary hyperinsulinism (tumoural or otherwise) to be undertaken, though the presence of acanthosis nigricans and severe hyperinsulinaemia should point towards a SSIR.

Hypoglycaemia is most commonly symptomatic in the postprandial state, though may commonly also be observed in the fasting state, and may be a feature of any form of SIR $(34,35,36)$. Because of this, fasting glucose levels may be normal or frankly low in the early stages of evaluation of a patient with a SSIR, contrasting with a blood glucose level in the diabetic range after an oral glucose challenge. The mechanism of hypoglycaemia in SSIRs is not clear, but a low-glycaemic index diet and acarbose, which blunts postprandial glucose and thus insulin excursion, may be helpful. However, comparative studies of these strategies are yet to be performed.

\section{Case 3: a muscular young adult with severe dyslipidaemia and abdominal pain}

A 21-year-old woman presented with a 12-h history of severe central abdominal pain radiating to her back. She reported previous similar but milder episodes over the preceding 2-3 years. A family history of non-insulindependent diabetes in her father was noted. She drank minimal quantities of alcohol and exercised infrequently. On inspection, she was lean with a BMI $23.5 \mathrm{~kg} / \mathrm{m}^{2}$. There was generalised paucity of subcutaneous adipose tissue on the limbs and torso, with evidence of previous breast augmentation surgery. The amount of adipose tissue was increased in the head and neck, giving a somewhat Cushingoid appearance, but there were no other clinical features of Cushing's syndrome. Indeed, 
far from showing muscle wasting peripherally, she was conspicuously muscular, most strikingly in her calves. There was moderate facial hirsutism as well as both nuchal and axillary acanthosis nigricans. Examination of the abdomen revealed pronounced epigastric tenderness, some distension and a palpable liver edge, with very quiet bowel sounds. There were no stigmata of chronic liver disease. On insertion of a urinary catheter, pronounced accumulation of labial adipose tissue, but no cliteromegaly, was noted.

Acute pancreatitis was suspected, but serum amylase levels were normal. Markedly lipaemic serum was reported, with evidence of a systemic inflammatory response, and abdominal computed tomography (CT) imaging showed a swollen pancreas consistent with pancreatitis. Fasting plasma triglyceride levels were later found to be $38 \mathrm{mmol} / \mathrm{l}$, with a fasting blood glucose level of $8.6 \mathrm{mmol} / \mathrm{l}$ and a plasma insulin level of $2300 \mathrm{pmol} / \mathrm{l}$.

After recovery from this acute episode, further evaluation showed adiponectin and leptin levels to be low at $2.3 \mathrm{mg} / \mathrm{l}$ (normal range 2.6-14.9) and $12 \mu \mathrm{g} / \mathrm{l}$ (normal range 14.9-60.2) respectively, while a liver ultrasound study was suggestive of hepatic steatosis. A T1-weighted magnetic resonance imaging (MRI) of the abdomen depicted a marked expansion of visceral adipose stores in stark contrast to the lack of abdominal subcutaneous adipose tissue. A clinical diagnosis of familial partial lipodystrophy type 2 (FPLD2) was made, and a heterozygous missense mutation, p.Arg482Trp, in the LMNA gene was identified.

Long-term management centred on dietary 'offloading' of adipose tissue through a low-fat, energybalanced diet, with adjunctive use of metformin. Fenofibrate therapy was initiated to help control persistent hypertriglyceridaemia, but leptin therapy was not considered initially in view of the baseline serum leptin levels $>12 \mu \mathrm{g} / \mathrm{l}$.

Comment This case illustrates several classical features of lipodystrophy. There may be a delay in recognising partial lipodystrophy, especially the commonest type described here, associated with LMNA mutations, because the amount of adipose tissue in the head and neck, and often in visceral depots, is increased (Fig. 3). Adiposity of the labia majora may also be markedly expanded and distressing in this condition. In other forms of partial lipodystrophy, some patients can have BMIs in the obese range. The adipose topography may have a Cushingoid appearance, and it is common for biochemical screening for Cushing's syndrome to have taken place prior to definitive diagnosis, although thin skin, easy bruising, striae and muscle atrophy are not the features of lipodystrophy.

Although imaging modalities such as MRI or body composition analyses using, for example, Dual-energy X-ray absorptiometry (DXA) or skinfold thickness, are sometimes used to substantiate a diagnosis of lipodystrophy, it remains predominantly a clinical diagnosis, made by inspection of patients in their underwear. This is especially
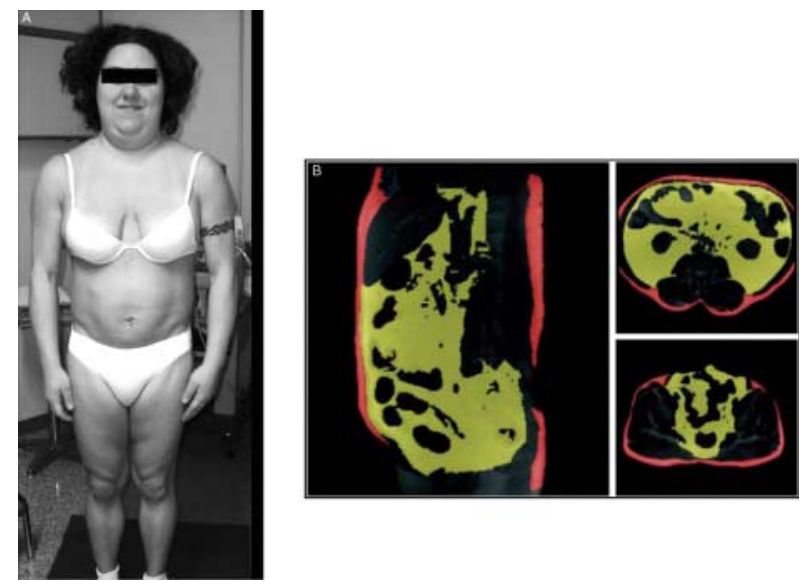

Figure 3 Familial partial lipodystrophy type 2. (A) Representative patient with FPLD2 at 21 years demonstrating lipoatrophy of limbs and calf hypertrophy with the preservation of head and neck adiposity giving rise to a 'Cushingoid' adipose topography (reproduced from (41)). (B) Sagittal and transverse T1-weighted MRI images of the abdomen depicting reduced subcutaneous fat (highlighted in red) and abundant visceral fat (highlighted in yellow) (reproduced from (68)).

true in partial lipodystrophies, where not uncommonly it is the disproportion between different adipose depots that is more striking than absolute deficiency in any one depot, manifest as relatively lean limbs with preserved or slightly increased truncal adiposity.

In view of the difficulty that may be encountered in confidently clinically discerning lipodystrophy, being alert to collateral clinical features that may aid diagnosis is of great importance, especially when evaluating the descriptions of other clinicians. The first such feature is unusually severe dyslipidaemia (low HDL cholesterol and high triglyceride levels), sometimes complicated by eruptive xanthomata and episodes of acute pancreatitis. Notably, serum amylase levels may be normal in the context of hypertriglyceridaemia-induced pancreatitis (37) and so should not be used as the basis for ruling it out. A feature associated with lipodystrophy is unusually severe and early-onset fatty liver disease, which may even progress to bridging fibrosis within the first decade of life in severe cases. A 'muscular appearance' is often commented on in women with lipodystrophy, which is due to the composite effects of the lack of limb adipose tissue and true muscular hypertrophy (38), the pathogenesis of which is yet to be elucidated.

Dietary management is the most critical element of managing lipodystrophy, with the aim being to 'offload' adipose tissue. This is achieved with low-fat, energybalanced or sometimes hypocaloric diets, which may have a dramatic effect on metabolic derangement. Indeed, a particular risk to lipodystrophic patients is the misinterpretation of their lack of adipose tissue as a sign of malnourishment, as well-meaning efforts to 'build them up' with calorie supplements may have severely adverse metabolic consequences. Thus, an experienced dietician is a critical part of the 
multidisciplinary team approach to lipodystrophy. Measures targeted wholly or in part at weight loss, including orlistat and glucagon-like peptide 1 analogue therapies and bariatric surgery (39), should be considered in poorly controlled lipodystrophic patients even when, as is likely, they are not obese; however, despite the strong rationale for this approach, largescale evidence for its efficacy is awaited.

Pharmacological therapies in lipodystrophic SSIRs should be aimed first at insulin sensitisation. Metformin is best established and should be titrated to the maximum tolerated dose. Thiazolidinediones may sometimes be effective $(40,41,42)$, but the best available evidence suggests that they require residual adipose depots to achieve metabolic benefit (43), and this may occur at the expense of the expansion of cosmetically distressing depots such as those in the head and neck. Thus, they should be used only with caution. Drugs aimed at reduction of hypertriglyceridaemia (e.g. fibrates) also have an important place in management.

In patients with lipodystrophy and low levels of serum leptin, s.c. administration of recombinant human leptin may be dramatically beneficial in improving glycaemic control, dyslipidaemia and hepatic lipid accumulation (43, $44,45,46,47)$. The patients to benefit most from this are those with generalised lipodystrophy and consequently extremely low or undetectable serum leptin levels. Some patients with partial lipodystrophy also benefit; however, the upper limit of pretreatment serum leptin levels that predicts a clinically meaningful response to therapy remains to be precisely defined. To date, it has been demonstrated that patients with partial lipodystrophy and features of severe metabolic derangement and leptin levels up to around $7 \mu \mathrm{g} / \mathrm{l}$ do benefit from leptin replacement, but further work is required to clarify the role of leptin in patients with higher leptin levels (48). It is important to appreciate that leptin is not a panacea for the metabolic treatment of lipodystrophy, however, and dietary noncompliance will severely attenuate the response to its use.

Leptin has been found to be well tolerated generally. The most serious adverse events associated with its use have been progressive renal disease and T-cell lymphoma, which has been reported in two patients (47). It remains unclear whether these adverse events are causally related to leptin therapy, as all the affected patients had acquired lipodystrophy and pre-existing active autoimmune disease. Nevertheless, as replacing leptin in hypoleptinaemic patients has been shown to exert stimulatory effects on T-lymphocyte function (49), due caution should be exercised when it is used in the context of active evidence of autoimmune disease.

\section{Case 4: a diabetic patient with acromegalic features}

A 50-year-old man with long-standing type 2 diabetes was evaluated for deteriorating glycaemic control. Initial presentation had been at 25 years of age with eruptive xanthomata, polyuria and polydipsia. Subsequently, he had developed treatment-resistant hypertension, renal dysfunction and hepatic steatosis. Jaw prognathism and large hands were repeatedly noted (Fig. 4), but no supporting biochemical evidence for acromegaly was found on multiple evaluations. Medications included 380 units of insulin/day, metformin, fenofibrate, fish oil and six different antihypertensive agents.

On inspection, acral enlargement, widely spaced teeth, prognathism and large hands were noted. His BMI was $33.6 \mathrm{~kg} / \mathrm{m}^{2}$ with predominantly central adipose distribution and relatively lean, muscular limbs. Mild acanthosis nigricans was present in both axillae. $\mathrm{HbA} 1 \mathrm{c}$ levels were $78 \mathrm{mmol} / \mathrm{mol}$ and lipid levels were well controlled. Serum insulin-like growth factor 1 (IGF1) levels were again within the normal range. A clinical diagnosis of SIR with pseudoacromegaly was made, and sequencing of the PPARG gene identified a frameshift mutation, confirming a diagnosis of FPLD3.

Comment Among the most striking differences between SSIRs and insulin deficiency is the range of overgrowth phenomena observed in the presence of hyperinsulinaemia. Acanthosis nigricans is the most common of these, giving the appearance of thickened, brown, 'velvety' skin in flexures, often associated with skin tags or acrochordons. In the most severe cases, it may be observed in perioral, periocular and buccal regions or even on planar surfaces. Unlike dyslipidaemia and fatty liver, acanthosis nigricans is observed in all known monogenic forms of SIR. Pseudoacromegalic soft tissue overgrowth is also well described, although observed in only some cases. It is most obvious in settings where there is concomitant lack of adipose tissue, but it is also observed in the context of obesity-related SIR. It is most likely that SIR/hyperinsulinaemia drives these growth

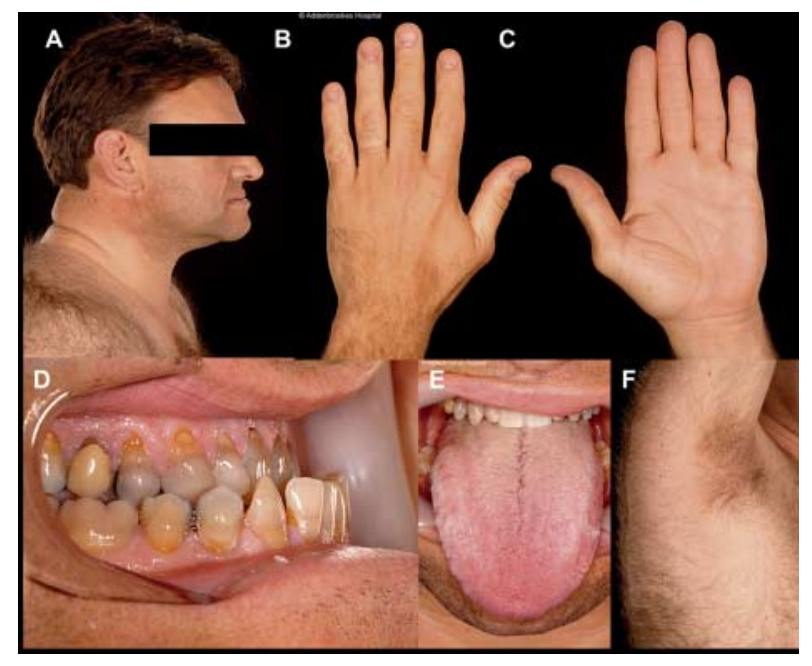

Figure 4 Case 4 showing pseudoacromegalic appearance of the $(A)$ face, (B and $C$ ) hands, $(D)$ mandible, $(E)$ tongue and $(F)$ axillary acanthosis nigricans. 
phenomena by augmenting mitogenic signalling through the IGF1 or other tyrosine kinase growth factor receptors, as there is cross talk between both endocrine and paracrine IGF1 signalling at multiple levels. For example, very high levels of insulin can act directly on the IGF1 receptor, while insulin action may also modulate the expression of the IGF1 receptor and bioavailability of IGF1 itself through alterations in binding protein levels. Nevertheless, formal proof of this notion, and understanding of the precise mechanism involved, is currently lacking.

\section{SSIRs presenting in prepubertal children}

Deranged blood glucose levels are often not the first features of prepubertal SSIRs that are recognised, unless hypoglycaemia is severe, as is often observed in infantile insulin receptor defects. Rather, problems with growth, or other syndromic features, tend to be the earliest problems to trigger investigation.

Donohue syndrome (formerly 'leprechaunism') (50) and Rabson-Mendenhall syndrome (51), the eponyms of which reflect their early clinical descriptions many decades before the identification of the insulin receptor, represent different parts of the spectrum of abnormality caused by autosomal recessive insulin receptor defects. In Donohue syndrome, little or no residual insulin receptor function is observed, while in RabsonMendenhall syndrome, receptor function is slightly less severely impaired. Clinical features of both syndromes have been thoroughly reviewed elsewhere (11, $51,52,53,54)$. In brief, it is often the failure to thrive, with a combination of impaired linear growth, underdevelopment of fat and muscle, and overgrowth of soft tissues including skin, hair, teeth and viscera, that is first noticed. Although postprandial hyperglycaemia, which may be severe, is the norm, fasting hypoglycaemia is also very common and may dominate the metabolic picture. Nephrocalcinosis, rectal prolapse and ventricular hypertrophy are common, and in girls, ovarian enlargement may be massive, in some cases complicated by the development of tumours. Surprisingly, infants with Donohue syndrome are protected from ketoacidosis initially (55), although this eventually supervenes after the first 2 or 3 years. In Donohue syndrome, death most commonly occurs during intercurrent infection, while in Rabson-Mendenhall syndrome, microvascular complications of diabetes in the second decade are the major threat.

Congenital generalised lipodystrophy is also usually apparent in infancy, sometimes being picked up in the early weeks of life by clinicians, but commonly first brought to their attention by mothers concerned about the 'wrinkly' and thin appearance of their babies, which may be coupled to muscular enlargement, accelerated growth and abdominal distension due to hepatic engorgement with triglycerides. Where adequate control is not achieved, congenital generalised lipodystrophy may give rise to some degree of irreversible liver fibrosis within the first one to two decades, and soft tissue overgrowth may also require surgical intervention. In general, FPLD does not become overtly clinically obvious until puberty, when body adipose tissue accretion gathers pace, especially in girls. However, few genetically affected individuals have been studied prepubertally, and, at least in the case of FPLD3 due to PPARG mutations, diabetes and dyslipidaemia may present well before 10 years of age $(35,56)$.

The final group of disorders commonly identified in the prepubertal years is that where SIR is only part of a larger constellation of problems. These include Alström syndrome (57), some forms of primordial dwarfism including osteodysplastic primordial dwarfism of Majewski type 2 (58), due to defects in the pericentrosomal protein pericentrin (59), and several forms of progeria or DNA damage repair disorders including Werner $(60,61)$ and Bloom (62) syndromes and

Table 2 Complex syndromes associated with severe insulin resistance.

\begin{tabular}{|c|c|c|c|c|}
\hline Syndrome & Gene(s) & Inheritance & Core clinical features & IR subphenotype \\
\hline $\begin{array}{l}\text { Alström (OMIM } \\
\text { \#203800) }\end{array}$ & ALMS1 & AR & $\begin{array}{l}\text { Rod-cone dystrophy, deafness, cardiomyopa- } \\
\text { thy and pulmonary/hepatic/renal dysfunction }\end{array}$ & Severe fatty liver and dyslipidaemia \\
\hline $\begin{array}{l}\text { MOPDII (OMIM } \\
\text { \#210720) }\end{array}$ & PCNT & AR & $\begin{array}{l}\text { Short stature, microcephaly, osteodysplasia } \\
\text { and Moyamoya vascular anomalies }\end{array}$ & Severe fatty liver and dyslipidaemia \\
\hline $\begin{array}{l}\text { Bloom (OMIM } \\
\text { \#210900) }\end{array}$ & $\begin{array}{r}R E C Q 2 \\
(B L M)\end{array}$ & AR & $\begin{array}{l}\text { Telangiectases, photosensitivity, short stature, } \\
\text { immunodeficiency and increased } \\
\text { susceptibility to cancer }\end{array}$ & Severe fatty liver and dyslipidaemia \\
\hline $\begin{array}{l}\text { Werner (OMIM } \\
\text { \#277700) }\end{array}$ & $\begin{array}{r}R E C Q L 2 \\
(W R M)\end{array}$ & AR & $\begin{array}{l}\text { Premature ageing, osteoporosis, cataracts, } \\
\text { atherosclerosis, increased susceptibility to } \\
\text { cancer and limb contractures }\end{array}$ & Severe fatty liver and dyslipidaemia \\
\hline $\begin{array}{l}\text { Mandibuloacral } \\
\text { dysplasia } \\
\text { (OMIM \#248370) }\end{array}$ & $\begin{array}{l}\text { LMNA } \\
\text { LMNA }\end{array}$ & AR & $\begin{array}{l}\text { Postnatal growth retardation, craniofacial and } \\
\text { skeletal abnormalities and cutaneous } \\
\text { pigmentation }\end{array}$ & Severe fatty liver and dyslipidaemia \\
\hline & ZMPSTE24 & & & \\
\hline
\end{tabular}

MOPDII, osteodysplastic primordial dwarfism of Majewski type II; AR, autosomal recessive. 
mandibuloacral dysplasia (63) (Table 2). The early natural history of the metabolic derangement in these conditions has not been studied in great detail, but cross-sectional assessments suggest that SIR is not congenital, but rather appears in the first few years of life. The metabolic phenotype in each of these conditions resembles that of lipodystrophy rather than that associated with insulin receptor defects. That is, extremely elevated levels of insulin are often accompanied by severe metabolic dyslipidaemia and fatty liver. However, while suggestive that the key defect may lie in the adipose tissue in these conditions, this evidence is circumstantial only, and the role of other key insulinresponsive tissues remains to be investigated.

\section{Management of prepubertal SSIRs}

The principles guiding the management of prepubertal SSIRs are broadly similar to those guiding the management of disease in older patients. Thus, in generalised lipodystrophy, minimising the dietary load of fat is essential, and careful nutritional follow-up is required to balance this with the demands of growth. As in older patients with absent adipose tissue, leptin replacement may have a major beneficial effect, and indeed there is a strong argument that early treatment from infancy may protect children with generalised lipodystrophy from accruing complications of poor metabolic control. However, case literature is only beginning to emerge in this group now (64).

In infants and children with SSIRs due to insulin signalling defects, recombinant human IGF1 has been widely used and appears to improve glycaemia and perhaps survival in some cases $(65,66)$. It has variously been proposed to exert beneficial effects through insulin mimetic activity, through action as a trophic factor for pancreatic $\beta$-cells, or by enhancing insulin sensitivity through postreceptor cross talk between insulin and IGF1 signalling pathways. Nevertheless, its dominant mode of action, optimal dosing and precise clinical indications for its use remain unclear.

\section{Declaration of interest}

The authors declare that there is no conflict of interest that could be perceived as prejudicing the impartiality of the review reported.

\section{Funding}

V E R Parker and R K Semple are funded by research fellowships from the Wellcome Trust (Clinical Research Training Fellowship 097721/Z/11/Z and Senior Research Fellowship in Clinical Science 098498/Z/12/Z respectively).

\section{Acknowledgements}

The authors are grateful to Prof. Steve O'Rahilly, Dr David Savage and colleagues in the UK National Severe Insulin Resistance Service for discussion and review of this manuscript.

\section{References}

1 Souren NY, Paulussen ADC, Loos RJF, Gielen M, Beunen G, Fagard R, Derom C, Vlietinck R \& Zeegers MP. Anthropometry, carbohydrate and lipid metabolism in the East Flanders Prospective Twin Survey: heritabilities. Diabetologia 200710 2107-2116. (doi:10.1007/s00125-007-0784-z)

2 Freeman MS, Mansfield MW, Barrett JH \& Grant PJ. Heritability of features of the insulin resistance syndrome in a community-based study of healthy families. Diabetic Medicine 200212 994-999. (doi:10.1046/j.1464-5491.2002.00843.x)

3 Mills GW, Avery PJ, McCarthy MI, Hattersley AT, Levy JC, Hitman GA, Sampson M \& Walker M. Heritability estimates for $\beta$ cell function and features of the insulin resistance syndrome in UK families with an increased susceptibility to type 2 diabetes. Diabetologia 20044 732-738. (doi:10.1007/s00125-004-1338-2)

4 Falchi M, Wilson SG, Paximadas D, Swaminathan R \& Spector TD. Quantitative linkage analysis for pancreatic $\beta$-cell function and insulin resistance in a large twin cohort. Diabetes 20084 1120-1124. (doi:10.2337/db07-0708)

5 Hanson RL, Imperatore G, Bennett PH \& Knowler WC. Components of the "metabolic syndrome" and incidence of type 2 diabetes. Diabetes 200210 3120-3127. (doi:10.2337/diabetes. 51.10.3120)

6 Utzschneider KM \& Kahn SE. Review: the role of insulin resistance in nonalcoholic fatty liver disease. Journal of Clinical Endocrinology and Metabolism 200612 4753-4761. (doi:10.1210/jc.20060587)

7 Siddique A \& Kowdley KV. Insulin resistance and other metabolic risk factors in the pathogenesis of hepatocellular carcinoma. Clinics in Liver Disease 201115 281-296 (vii-x). (doi:10.1016/ j.cld.2011.03.007)

8 Resnick HE, Jones K, Ruotolo G, Jain AK, Henderson J, Lu W \& Howard BV. Insulin resistance, the metabolic syndrome, and risk of incident cardiovascular disease in nondiabetic American Indians: the Strong Heart Study. Diabetes Care 20033 861-867. (doi:10.2337/diacare.26.3.861)

9 Dunaif A, Segal KR, Futterweit W \& Dobrjansky A. Profound peripheral insulin resistance, independent of obesity, in polycystic ovary syndrome. Diabetes 19899 1165-1174. (doi:10.2337/ diabetes.38.9.1165)

10 Pollack MN. Insulin, insulin-like growth factors, insulin resistance, and neoplasia. American Journal of Clinical Nutrition 20073 s820-s822.

11 Semple RK, Savage DB, Cochran EK, Gorden P \& O'Rahilly S. Genetic syndromes of severe insulin resistance. Endocrine Reviews 20114 498-514. (doi:10.1210/er.2010-0020)

12 Flier JS, Kahn CR, Jarrett DB \& Roth J. Characterization of antibodies to the insulin receptor: a cause of insulin-resistant diabetes in man. Journal of Clinical Investigation $1976 \mathbf{6}$ 1442-1449. (doi:10.1172/JCI108600)

13 Arioglu E, Andewelt A, Diabo C, Bell M, Taylor SI \& Gorden P. Clinical course of the syndrome of autoantibodies to the insulin receptor (type B insulin resistance): a 28-year perspective. Medicine 20022 87-100. (doi:10.1097/00005792-200 203000-00001)

14 Sissons JG, West RJ, Fallows J, Williams DG, Boucher BJ, Amos N \& Peters DK. The complement abnormalities of lipodystrophy. New England Journal of Medicine 19769 461-465. (doi:10.1056/ NEJM197602262940902)

15 Savage DB, Semple RK, Clatworthy MR, Lyons PA, Morgan BP, Cochran EK, Gorden P, Raymond-Barker P, Murgatroyd PR, Adams C et al. Complement abnormalities in acquired lipodystrophy revisited. Journal of Clinical Endocrinology and Metabolism 2009 1 10-16.

16 Misra A, Peethambaram A \& Garg A. Clinical features and metabolic and autoimmune derangements in acquired partial lipodystrophy: report of 35 cases and review of the literature. Medicine 20041 18-34. (doi:10.1097/01.md.0000111061. 69212.59) 
17 Misra A \& Garg A. Clinical features and metabolic derangements in acquired generalized lipodystrophy: case reports and review of the literature. Medicine 20032 129-146. (doi:10.1097/ 00005792-200303000-00007)

18 Garg A. Acquired and inherited lipodystrophies. New England Journal of Medicine 200412 1220-1234. (doi:10.1056/ NEJMra025261)

19 Larsen J \& Goldner W. Approach to the hospitalized patient with severe insulin resistance. Journal of Clinical Endocrinology and Metabolism 2011 9 2652-2662. (doi:10.1210/jc.2011-0255)

20 Raffan E \& Semple RK. Next generation sequencing - implications for clinical practice. British Medical Bulletin 201199 53-71. (doi:10.1093/bmb/ldr029)

21 Parker VER, Savage DB, O'Rahilly S \& Semple RK. Mechanistic insights into insulin resistance in the genetic era. Diabetic Medicine 201112 1476-1486. (doi:10.1111/j.1464-5491. 2011.03463.x)

22 Savage DB, Semple RK, Chatterjee VKK, Wales JKH, Ross RJM \& O'Rahilly S. A clinical approach to severe insulin resistance. Endocrine Development $2007 \quad 11$ 122-132. (doi:10.1159/ 000111067)

23 Semple RK, Soos MA, Luan J, Mitchell CS, Wilson JC, Gurnell M, Cochran EK, Gorden P, Chatterjee VKK, Wareham NJ et al. Elevated plasma adiponectin in humans with genetically defective insulin receptors. Journal of Clinical Endocrinology and Metabolism 20068 3219-3223. (doi:10.1210/jc.2006-0166)

24 Semple RK, Sleigh A, Murgatroyd PR, Adams CA, Bluck L, Jackson S, Vottero A, Kanabar D, Charlton-Menys V, Durrington P et al. Postreceptor insulin resistance contributes to human dyslipidemia and hepatic steatosis. Journal of Clinical Investigation 20092 315-322. (doi:10.1172/JCI37432)

25 Poretsky L, Cataldo NA, Rosenwaks Z \& Giudice LC. The insulinrelated ovarian regulatory system in health and disease. Endocrine Reviews 19994 535-582. (doi:10.1210/er.20.4.535)

26 Nestler JE \& Jakubowicz DJ. Decreases in ovarian cytochrome P450c $17 \alpha$ activity and serum free testosterone after reduction of insulin secretion in polycystic ovary syndrome. New England Journal of Medicine 19969 617-623. (doi:10.1056/ NEJM199608293350902)

27 Koroscil TM, Harter SB, Ouweleen J \& Blauer KL. Use of a gonadotropin-releasing hormone agonist in the evaluation of postmenopausal virilization due to ovarian hyperthecosis. A case report. Journal of Reproductive Medicine 19964 259-262.

28 Pascale MM, Pugeat M, Roberts M, Rousset H, Déchaud H, Dutrieux-Berger N \& Tourniaire J. Androgen suppressive effect of GnRH agonist in ovarian hyperthecosis and virilizing tumours. Clinical Endocrinology 19945 571-576. (doi:10.1111/j.13652265.1994.tb01820.x)

29 Chico A, García JL, Matías-Guiu X, Webb SM, Rodríguez J, Prat J \& Calaf J. A gonadotrophin dependent stromal luteoma: a rare cause of post-menopausal virilization. Clinical Endocrinology $1995 \mathbf{5}$ 645-649. (doi:10.1111/j.1365-2265.1995.tb02931.x)

30 Brisigotti M, Fabbretti G, Pesce F, Gatti R, Cohen A, Parenti G \& Callea F. Congenital bilateral juvenile granulosa cell tumor of the ovary in leprechaunism: a case report. Pediatric Pathology 19935 549-558. (doi:10.3109/15513819309048242)

31 Antuna-Puente B, Boutet E, Vigouroux C, Lascols O, Slama L, Caron-Debarle M, Khallouf E, Lévy-Marchal C, Capeau J, Bastard JP et al. Higher adiponectin levels in patients with Berardinelli-Seip congenital lipodystrophy due to seipin as compared with 1-acylglycerol-3-phosphate-o-acyltransferase-2 deficiency. Journal of Clinical Endocrinology and Metabolism 2010 3 1463-1468. (doi:10.1210/jc.2009-1824)

32 Hattori Y, Hirama N, Suzuki K, Hattori S \& Kasai K. Elevated plasma adiponectin and leptin levels in sisters with genetically defective insulin receptors. Diabetes Care $2007 \mathbf{1 1}$ e109. (doi:10.2337/dc07-1342)

33 Semple RK, Cochran EK, Soos MA, Burling KA, Savage DB, Gorden P \& O'Rahilly S. Plasma adiponectin as a marker of insulin receptor dysfunction: clinical utility in severe insulin resistance. Diabetes Care 20085 977-979. (doi:10.2337/dc07-2194)
34 Højlund K, Hansen T, Lajer M, Henriksen JE, Levin K, Lindholm J, Pedersen $O$ \& Beck-Nielsen H. A novel syndrome of autosomaldominant hyperinsulinemic hypoglycemia linked to a mutation in the human insulin receptor gene. Diabetes 20046 1592-1598. (doi:10.2337/diabetes.53.6.1592)

35 Agostini M, Schoenmakers E, Mitchell C, Szatmari I, Savage D, Smith A, Rajanayagam O, Semple R, Luan J, Bath L et al. Non-DNA binding, dominant-negative, human PPAR $\gamma$ mutations cause lipodystrophic insulin resistance. Cell Metabolism 20064 303311. (doi:10.1016/j.cmet.2006.09.003REF8 $=10.2337 /$ diacare. 26.3.861)

36 George S, Rochford JJ, Wolfrum C, Gray SL, Schinner S, Wilson JC, Soos MA, Murgatroyd PR, Williams RM, Acerini CL et al. A family with severe insulin resistance and diabetes due to a mutation in AKT2. Science 20045675 1325-1328. (doi:10.1126/science. 1096706)

37 Sharma P, Lim S, James D, Orchard RT, Horne M \& Seymour CA. Pancreatitis may occur with a normal amylase concentration in hypertriglyceridaemia. BMJ 19967067 1265. (doi:10.1136/bmj. 313.7067.1265)

38 Ji H, Weatherall P, Adams-Huet B \& Garg A. Increased skeletal muscle volume in women with familial partial lipodystrophy, Dunnigan variety. Journal of Clinical Endocrinology and Metabolism 2013. In press. (doi:10.1210/jc.2013-1297)

39 Ciudin A, Baena-Fustegueras JA, Fort JM, Encabo G, Mesa J \& Lecube A. Successful treatment for the Dunnigan-type familial partial lipodystrophy with Roux-en-Y gastric bypass. Clinical Endocrinology 20113 403-404. (doi:10.1111/j.13652265REF13=10.1097/00005792-200203000-00001)

40 Owen KR, Donohoe M, Ellard S \& Hattersley AT. Response to treatment with rosiglitazone in familial partial lipodystrophy due to a mutation in the LMNA gene. Diabetic Medicine 200310 823-827. (doi:10.1046/j.1464-5491.2003.01034.x)

41 Gambineri A, Semple RK, Forlani G, Genghini S, Grassi I, Hyden CSS, Pagotto U, O'Rahilly S \& Pasquali R. Monogenic polycystic ovary syndrome due to a mutation in the lamin $\mathrm{A} / \mathrm{C}$ gene is sensitive to thiazolidinediones but not to metformin. European Journal of Endocrinology 20083 347-353. (doi:10REF16 $=10.1097 / 01 . \mathrm{md} .0000111061 .69212 .59$ )

42 Sleilati GG, Leff T, Bonnett JW \& Hegele RA. Efficacy and safety of pioglitazone in treatment of a patient with an atypical partial lipodystrophy syndrome. Endocrine Practice 2007136. (doi:10.4158/EP.13.6.656)

43 Simha V, Rao S \& Garg A. Prolonged thiazolidinedione therapy does not reverse fat loss in patients with familial partial lipodystrophy, Dunnigan variety. Diabetes, Obesity \& Metabolism 200812 1275-1276. (doi:10.1111/j.1463-1326.2008.00978.x)

44 Javor ED, Cochran EK, Musso C, Young JR, Depaoli AM \& Gorden P. Long-term efficacy of leptin replacement in patients with generalized lipodystrophy. Diabetes 20057 1994-2002. (doi:10. 2337/diabetes.54.7.1994)

45 Petersen KF, Oral EA, Dufour S, Befroy D, Ariyan C, Yu C, Cline GW, DePaoli AM, Taylor SI, Gorden P et al. Leptin reverses insulin resistance and hepatic steatosis in patients with severe lipodystrophy. Journal of Clinical Investigation 200210 1345-1350. (doi:10.1172/JCI15001)

46 Chong AY, Lupsa BC, Cochran EK \& Gorden P. Efficacy of leptin therapy in the different forms of human lipodystrophy. Diabetologia 20101 27-35. (doi:10.1007/s00125-009-1502-9)

47 Chan JL, Lutz K, Cochran E, Huang W, Peters Y, Weyer C \& Gorden P. Clinical effects of long-term metreleptin treatment in patients with lipodystrophy. Endocrine Practice 20116 922-932. (doi:10.4158/EP11229.OR)

48 Simha V, Subramanyam L, Szczepaniak L, Quittner C, AdamsHuet B, Snell P \& Garg A. Comparison of efficacy and safety of leptin replacement therapy in moderately and severely hypoleptinemic patients with familial partial lipodystrophy of the Dunnigan variety. Journal of Clinical Endocrinology and Metabolism 20123 785-792. (doi:10.1210/jc.2011-2229)

49 Matarese G, La Rocca C, Moon HS, Huh JY, Brinkoetter MT, Chou S, Perna F, Greco D, Kilim HP, Gao C et al. Selective capacity 
of metreleptin administration to reconstitute CD4+T-cell number in females with acquired hypoleptinemia. PNAS 20139 E818-E827. (doi:10.1073/pnas.1214554110)

50 Donohue WL \& Uchida I. Leprechaunism: a euphemism for a rare familial disorder. Journal of Pediatrics 19545 505-519.

51 Rabson SM \& Mendenhall EN. Familial hypertrophy of pineal body, hyperplasia of adrenal cortex and diabetes mellitus; report of 3 cases. American Journal of Clinical Pathology 19563 283-290.

52 Musso C, Cochran E, Moran SA, Skarulis MC, Oral EA, Taylor S \& Gorden P. Clinical course of genetic diseases of the insulin receptor (type A and Rabson-Mendenhall syndromes): a 30-year prospective. Medicine 20044 209-222. (doi:10.1097/01.md.0000 $133625.73570 .54)$

53 Accili D, Cama A, Barbetti F, Kadowaki H, Kadowaki T \& Taylor SI. Insulin resistance due to mutations of the insulin receptor gene: an overview. Journal of Endocrinological Investigation 199211 857-864.

54 Semple RK, Williams RM \& Dunger DB. What is the best management strategy for patients with severe insulin resistance? Clinical Endocrinology 20103 286-290. (doi:10.1111/j.13652265.2010.03810.x)

55 Ogilvy-Stuart AL, Soos MA, Hands SJ, Anthony MY, Dunger DB \& O'Rahilly S. Hypoglycemia and resistance to ketoacidosis in a subject without functional insulin receptors. Journal of Clinical Endocrinology and Metabolism 20017 3319-3326. (doi:10.1210/ jc.86.7.3319)

56 Madhra M, Noh RM, Zammitt NN, Patrick AW \& Love CD. A complicated pregnancy in a patient with lipodystrophic diabetes attributable to a peroxisome proliferator-activated receptor $\gamma$ (PPARG) mutation. Diabetic Medicine 201210 e398-e401. (doi:10.1111/j.1464-5491.2012.03742.x)

57 Marshall JD, Paisey RB, Carey C, \& Macdermott S. Alström Syndrome. 2003 Feb 7 [Updated 2012 May 31]. In: Pagon RA, Adam MP, Bird TD, et al., editors. GeneReviews ${ }^{\mathrm{TM}}$ [Internet]. Seattle (WA): University of Washington, Seattle; 1993-2013.

58 Huang-Doran I, Bicknell LS, Finucane FM, Rocha N, Porter KM, Tung YCL, Szekeres F, Krook A, Nolan JJ, O’Driscoll M et al. Genetic defects in human pericentrin are associated with severe insulin resistance and diabetes. Diabetes 20113 925-935. (doi:10.2337/db10-1334)

59 Rauch A, Thiel CT, Schindler D, Wick U, Crow YJ, Ekici AB, Van Essen AJ, Goecke TO, Al-Gazali L, Chrzanowska KH et al. Mutations in the pericentrin (PCNT) gene cause primordial dwarfism. Science $2008 \mathbf{5 8 6 4} 816-819$. (doi:10.1126/science. 1151174)
60 Yamada K, Ikegami H, Yoneda H, Miki T \& Ogihara T. All patients with Werner's syndrome are insulin resistant, but only those who also have impaired insulin secretion develop overt diabetes. Diabetes Care 199912 2094-2095. (doi:10.2337/diacare.22. 12.2094)

61 Imura H, Nakao Y, Kuzuya H, Okamoto M \& Yamada K. Clinical, endocrine and metabolic aspects of the Werner syndrome compared with those of normal aging. Advances in Experimental Medicine and Biology 1985190 171-185. (doi:10.1007/978-14684-7853-2_6)

62 Diaz A, Vogiatzi MG, Sanz MM \& German J. Evaluation of short stature, carbohydrate metabolism and other endocrinopathies in Bloom's syndrome. Hormone Research 20063 111-117. (doi:10.1159/000093826)

63 Jacob KN \& Garg A. Laminopathies: multisystem dystrophy syndromes. Molecular Genetics and Metabolism 2006 4 289-302. (doi:10.1016/j.ymgme.2005.10.018)

64 Beltrand J, Beregszaszi M, Chevenne D, Sebag G, De Kerdanet M, Huet F, Polak M, Tubiana-Rufi N, Lacombe D, De Paoli AM et al. Metabolic correction induced by leptin replacement treatment in young children with Berardinelli-Seip congenital lipoatrophy. Pediatrics 20072 e291-e296. (doi:10.1542/peds.2006-3165)

65 Regan FM, Williams RM, McDonald A, Umpleby AM, Acerini CL, O'Rahilly S, Hovorka R, Semple RK \& Dunger DB. Treatment with recombinant human insulin-like growth factor (rhIGF)-I/rhIGF binding protein-3 complex improves metabolic control in subjects with severe insulin resistance. Journal of Clinical Endocrinology and Metabolism 2010 5 2113-2122. (doi:10.1210/jc.2009-2088)

66 McDonald A, Williams RM, Regan FM, Semple RK \& Dunger DB. IGF-I treatment of insulin resistance. European Journal of Endocrinology 2007157 (Suppl) S51-S56. (doi:10.1530/ EJE-07-0271)

67 Wareham NJ, Byrne CD, Williams R, Day NE \& Hales CN. Fasting proinsulin concentrations predict the development of type 2 diabetes. Diabetes Care 19992 262-270. (doi:10.2337/diacare. 22.2.262)

68 Huang-Doran I, Sleigh A, Rochford JJ, O’Rahilly S \& Savage DB. Lipodystrophy: metabolic insights from a rare disorder. Journal of Endocrinology 20103 245-255. (doi:10.1677/JOE-10-0272)

Received 16 April 2013

Revised version received 3 July 2013

Accepted 12 July 2013 